\title{
The relationships between glycemic index and glycemic load of diets and nutritional status and antioxidant/oxidant status in the serum of patients with lung cancer
}

\author{
Katarzyna Agnieszka Zabłocka-Słowińska, ${ }^{1, A-D, F}$, Katarzyna Skórska ${ }^{1, A-D, F, ~ S y l w i a ~ P ł a c z k o w s k a ~ 2, B, C, E, ~}$ \\ Anna Prescha ${ }^{1, B}$, Konrad Pawełczyk ${ }^{3, B, E}$, Monika Kosacka ${ }^{4, B, E}$, Irena Porębska ${ }^{4, B, E}$, Halina Grajeta ${ }^{1, E, F}$ \\ ${ }^{1}$ Department of Food Science and Nutrition, Wroclaw Medical University, Poland \\ ${ }^{2}$ Diagnostics Laboratory for Teaching and Research, Wroclaw Medical University, Poland \\ ${ }^{3}$ Department and Clinic of Thoracic Surgery, Wroclaw Medical University, Poland \\ ${ }^{4}$ Department and Clinic of Pulmonology and Lung Cancers, Wroclaw Medical University, Poland \\ A - research concept and design; $\mathrm{B}$ - collection and/or assembly of data; $\mathrm{C}$ - data analysis and interpretation; \\ $\mathrm{D}$ - writing the article; $\mathrm{E}$ - critical revision of the article; $\mathrm{F}$ - final approval of the article
}

Address for correspondence

Katarzyna Zabłocka

E-mail:katarzyna.zablocka-slowinska@umed.wroc.pl

Funding sources

None declared

Conflict of interest

None declared

Received on July 3, 2018

Reviewed on September 28, 2018

Accepted on October 14, 2018

Published online on March 9, 2019

Cite as

Zabłocka-Słowińska KA, Skórska K, Płaczkowska S, et al. The relationships between glycemic index and glycemic load of diets and nutritional status and antioxidant/oxidant status in the serum of patients with lung cancer. Adv Clin Exp Med. 2019;28(8):1027-1036. doi:10.17219/acem/98952

DOI

10.17219/acem/98952

Copyright

Copyright by Author(s)

This is an article distributed under the terms of the

Creative Commons Attribution Non-Commercial License

(http://creativecommons.org/licenses/by-nc-nd/4.0/)

\begin{abstract}
Background. A low glycemic index (GI) and glycemic load (GL) of diets as well as proper nutritional status may partially slow down depletion in antioxidant capacity, and may therefore have an impact on antioxidant/ oxidant status in lung cancer patients. However, no studies concerning these associations had previously been conducted.
\end{abstract}

Objectives. The aim of this study was to investigate the association between $\mathrm{Gl}$ or $\mathrm{GL}$ and nutritional status and antioxidant/oxidant status in lung cancer patients.

Material and methods. The study was conducted among 180 lung cancer patients ( 82 women and 98 men) and 171 control subjects (78 women and 93 men). Exclusion criteria for the control subjects included cancers, pro-inflammatory conditions, brain diseases, and psychiatric disorders. All participants were evaluated in terms of their systemic antioxidant/oxidant status, nutritional status (anthropometric parameters), dietary $\mathrm{Gl}$ and $\mathrm{GL}$ and parameters related to circulating glucose: fasting glucose, insulin level and homeostasis model assessment for insulin resistance (HOMA-IR).

Results. In women who were lung cancer-positive, associations were observed between total antioxidant status (TAS) and parameters of nutritional status, and between oxidative stress index (OSI) and fasting glucose. In men with lung cancer, we found a positive correlation between total oxidant status (TOS) and Gl. In the control group of women, TAS positively correlated with anthropometric parameters, but negatively with dietary fiber and total carbohydrate content. Additionally, TOS and OSI negatively correlated with parameters related to body weight and positively with insulin. In control men, we observed significant negative correlations between parameters related to fasting glucose and TAS and positive ones with TOS and OSI.

Conclusions. The results show that in lung cancer oxidative stress is related to Gl, while TAS is related to nutritional status. Further investigations performed on a larger cohort are required to better clarify the observed relationships as well as to explain the potential mechanisms involved.

Key words: lung cancer, nutritional status, oxidative stress, glycemic load, glycemic index 


\section{Introduction}

The most recent global cancer statistics indicate that lung cancer is still the most commonly diagnosed cancer in men in countries of low socioeconomic status. Regardless of the economic status of the country, it remains the most common cause of oncological deaths for both sexes. ${ }^{1}$ In Poland, as in the rest of the world, lung cancer is a major cause of cancer-related deaths, although incidences of lung cancer in men are decreasing gradually, in contrast to incidences observed among women, which continue to rise. The National Cancer Register shows that in 2013 more than 14,000 men and almost 7,000 women were diagnosed with lung cancer. ${ }^{2}$

Lung cancer is most effectively prevented by avoiding active and passive smoking. ${ }^{3}$ Additional risk factors include environmental pollution, chronic obstructive pulmonary disease and other inflammatory-related respiratory diseases, as well as genetic predisposition. A well-balanced diet rich in vegetable and fruit products, and regular, moderate physical activity may additionally potentiate the prevention of lung cancerogenesis., ${ }^{4,5}$

At the molecular level, oxidative stress plays an important role in lung cancer pathogenesis. ${ }^{6}$ Lungs are especially susceptible to pro-oxidative environments caused by factors such as high atmospheric oxygen pressure, the high amount of reactive species generated by pro-inflammatory cells in pulmonary circulation and air xenobiotics, e.g., from air pollution and/or tobacco smoke. ${ }^{7,8}$ In lung cancer patients, some mechanisms may induce disturbances in redox homeostasis, e.g., cancer-related chronic inflammation and malnutrition. ${ }^{9}$ Oxidative stress in malnourished cancer patients may also be caused by protein, carbohydrate and lipid metabolic alterations, which on the one hand intensify oxidative stress and therefore deplete the antioxidant capacity of the body, but on the other hand impair the synthesis of protein-related reducing agents due to an increased whole body protein turnover. ${ }^{10,11}$ Additionally, lessened dietary antioxidant intake and imbalanced dietary habits in general have been demonstrated many times to deepen redox imbalance in healthy people, while data on oncology patients is inconclusive. ${ }^{12,13}$ High dietary glycemic index (GI) and glycemic load (GL) may be associated with systemic oxidative stress. ${ }^{14} \mathrm{~A}$ disruption in antioxidant/oxidant status observed under high GI and/or GL may be the result of increased blood glucose concentration and insulin level, which can promote glucose intolerance, insulin resistance, hyperglycemia, and hyperinsulinemia. Hyperglycemia and hyperinsulinemia may lead to oxidative stress independently of other factors. ${ }^{15}$

To the best of our knowledge, no studies concerning the association between the GI and the GL of diets or nutritional status and antioxidant/oxidant status in lung cancer patients have previously been carried out. The authors of this study hypothesize that diets based on low GI and GL and proper nutritional status may partially slow down depletion in antioxidant capacity and therefore have an impact on antioxidant/oxidant status. Based on the assumptions presented above, finding any potential relationships between GI, GL or nutritional status and antioxidant/oxidant status in lung cancer patients may enhance the management of lung cancer and create an opportunity for more personalized oncological care, including dietary recommendations.

Considering the above, the aim of this study was to investigate the association between GI, GL and nutritional status and antioxidant/oxidant status in lung cancer patients.

\section{Material and methods}

\section{Material}

The study was conducted among 82 women with lung cancer (lung cancer women - LW) at a median age of 66 years (range: 41-82 years) and 98 men with lung cancer (lung cancer men - LM) at a median age of 66 years (range: 41-82 years), before any cancer treatment. All detailed information about the lung cancer patients (clinical stage of the disease, type of cancer, smoking status, and educational level) are presented in Table 1 . The clinical stages of disease were evaluated using the TNM classification. The clinical stage and metastases were determined with chest computed tomography (CT), positron emission tomography/CT (PET/CT) and ultrasonography (USG) of the abdominal cavity. Computed tomography/magnetic resonance imaging (CT/MRI) of the central nervous system (CNS) and scintigraphy of bone were performed when necessary. Bronchial fibroscopy was carried out routinely. In the case of enlarged lymph nodes of the mediastinum, an endobronchial ultrasound transbronchial needle aspiration (EBUS-TBNA) was performed. Negative EBUS results were verified in mediastinoscopy. Histological typing of lung cancer was performed by pathologists through microscopic evaluation.

The lung cancer group (LG) was recruited from the Lower Silesian Center of Lung Diseases, Wrocław, Poland. The control group (CG) consisted of 78 women (control women $-\mathrm{CW}$ ) at a median age of 56 years (range: 24-77 years) and 93 men (control men - CM) at a median age of 59 years (range: 23-98 years), recruited from the Wrocław $3^{\text {rd }}$ Age Universities, the Center of Occupational Medicine in Wrocław and from Wroclaw Medical University employees. Exclusion criteria for the control group included cancers, pro-inflammatory diseases, autoimmune diseases, gastrointestinal disorders, skin disorders, brain diseases, and psychiatric disorders. The subject's health condition was self-reported. Data on the level of education and smoking status of both the lung cancer patients and the control subjects was also self-reported. The lung cancer patients and control 
subjects were asked whether they were current smokers, former smokers (at least 2 weeks without active smoking) or never-smokers.

\section{Methods}

\section{Blood collection and preparation}

The day after a lung cancer patient's admission to hospital, blood samples were collected during a fasting state and the serum was separated and then stored at $-80^{\circ} \mathrm{C}$ prior to analysis. In the control subjects, blood was collected after overnight fasting at the Diagnostic Laboratory for Teaching and Research or at the Center of Occupational Medicine by a professional (medical analyst). The study protocol was approved by the Ethics Commission of the Wroclaw Medical University (approval No. 540/2013), and the study was conducted according to the principles expressed in the Declaration of Helsinki. All participants provided written consent for taking part in the research.

\section{Biochemical variable measurements in serum}

\section{Total antioxidant status}

Total antioxidant status (TAS) [mmol Trolox equiv./L] was measured in serum by the generation of 2,2'-azinodi-(3-ethylbenzthiazoline sulphonate) (ATBS) radical cation using a commercial TAS kit (Randox Laboratories, Crumlin, UK).

\section{Total oxidant status}

Total oxidant status (TOS) $\left[\mu \mathrm{mol} \mathrm{H}_{2} \mathrm{O}_{2} / \mathrm{L}\right]$ was measured as described by Erel. ${ }^{16}$ In this method, the oxidants present in the sample oxidize the ferrous ion-o-dianisidine complex to ferric ion. Ferric ion produces a colored complex with xylenol orange in an acidic medium. The color intensity is related to the total activity of oxidants present in the sample. The assay was calibrated with hydrogen peroxide and the results were expressed in terms of $\mu \mathrm{mol}$ $\mathrm{H}_{2} \mathrm{O}_{2}$ equivalent/ $\mathrm{L}$ of serum.

\section{Oxidative stress index}

The TOS:TAS ratio was used as the oxidative stress index (OSI), and was calculated as follows ${ }^{17}$ :

$$
\text { OSI [arbitrary unit }]=\frac{\operatorname{TOS}\left[\mu \mathrm{mol} \mathrm{H}_{2} \mathrm{O}_{2} / \mathrm{L}\right]}{\operatorname{TAS}[\mathrm{mmol} \text { Trolox equiv./L }]}
$$

\section{Malondialdehyde}

Serum malondialdehyde concentration (MDA) $[\mu \mathrm{mol} / \mathrm{L}]$ was measured based on a reaction with thiobarbituric acid (TBA) and extraction with 1-butanol after heating in boiling water for $45 \mathrm{~min}$. The absorbance of the pink supernatant was measured at $535 \mathrm{~nm}$, and the results were calculated using the molar coefficient and were expressed in $\mu \mathrm{mol}$ of $\mathrm{MDA} / \mathrm{L}$ of serum.

\section{Glucose}

Glucose concentration (GLC) [mg/dL] was quantified with a commercial kit (cat. No. 981780; Thermo Fisher Scientific, Waltham, USA), based on an enzymatic coupled assay using glucose oxidase and the peroxidase method (GOD-POD).

Insulin

Insulin concentration $[\mu \mathrm{U} / \mathrm{mL}]$ was determined with a DRG Insulin enzyme-linked immunosorbent assay (ELISA) (cat. No. EIA-2935; DRG Instruments GmbH, Marburg, Germany). The test is based on the sandwich principle.

Homeostasis model assessment for insulin resistance

Homeostasis model assessment for insulin resistance (HOMA-IR) was calculated using the equation ${ }^{18}$ :

$$
\text { HOMA-IR }=\frac{\begin{array}{l}
(\text { fasting insulin }[\mu \mathrm{U} / \mathrm{mL}] \times \\
\times \text { fasting glucose }[\mathrm{mg} / \mathrm{dL}])
\end{array}}{405 \text { [arbitrary unit] }}
$$

\section{Nutritional status}

Anthropometric parameters were used to assess the nutritional status of the participants. Baseline anthropometric parameters were measured: weight, height, body fat percentage (BFP), waist circumference (WC), hip circumference (HC), waist-hip ratio (WHR), mid-arm circumference (MAC), and calf circumference (CC). Body mass index (BMI) was calculated as the weight in kilograms divided by the square of the height in meters $\left[\mathrm{kg} / \mathrm{m}^{2}\right]$. The percentage of body fat was determined using a Body FAT Monitor (Omron BF 306; Omron, Kyoto, Japan).

Fat free mass index (FFMI) was calculated from the following formula ${ }^{19}$ :

$$
\text { FFMI }=(100 \%-\text { BFP }) / 100 \times \text { weight } / \text { height }^{2}
$$

Waist circumference was measured at the level of the umbilicus, and hip circumference was measured at the trochanter level. The WHR was calculated as the ratio of waist circumference to hip circumference. The MAC was measured with a millimeter tape at the midpoint of the non-dominant arm, between the olecranon and acromion. The CC was measured with wrapping the tape around the widest part of the calf with the patient in a sitting position, left knee raised at a right angle, and the calf uncovered by rolling up the subject's pant leg. All anthropometric measurements were performed twice.

\section{Dietary intakes}

Dietary data was gathered for all study participants using 72-hour dietary recalls by a trained interviewer. ${ }^{20}$ In the case of LG, the interview was carried out on the day of hospital admission. To assess the portion size of food products, the "Album of Photographs of Food Products and Dishes" was used. ${ }^{21}$ All dietary recalls were analyzed using 
Microsoft Excel 365 (Microsoft Corp., Redmond, USA). The daily energy value of the diets, the amount of total and available carbohydrates and dietary fiber were taken from the "Tables of Composition and Nutritional Value". ${ }^{22}$ The GI values were assigned to individual food items using a method described by Louie et al. ${ }^{23}$ The GI values were sourced from one of the following GI databases: the International Tables of Glycemic Index and Glycemic Load Values: 2008 (Atkinson et al. database), ${ }^{24}$ the Glycemic Index site of the University of Sydney www.glycemicindex.com ${ }^{25}$ and the National Cancer Institute (NCI) database. ${ }^{26}$ We used the following equations to calculated GI and GL value:

Glycemic load (GL) of diets ${ }^{23}$ :

GI $\times$ amount (in grams) of available carbohydrate in a serve of that food 100

Glycemic index (GI \%) of diets ${ }^{23}$ :

$\mathrm{GL} \times 100 \%$

amount (in grams) total carbohydrate in a serve of that food

\section{Statistical analysis}

The data was analyzed using STATISTICA v. 12.0 (StatSoft Inc., Tulsa, USA). All parameters are presented as a median and range. For all statistical procedures, the significance level was considered to be $\mathrm{p}<0.05$. Most of the results obtained did not present normal distribution, as confirmed by the Shapiro-Wilk test. Student's t-test for parametric data or the Mann-Whitney U test for nonparametric data were performed to evaluate the differences in baseline characteristics, anthropometric parameters, nutrient intakes, and GI and the GL of diets between LG and CG. A $X^{2}$ test was used to compare the level of education and cigarette smoking status between LG and CG.
The correlations between anthropometric parameters, GI and GL of diets and nutrient intakes, as well as biochemical variables related to serum glucose and antioxidant/ oxidant status parameters were assessed using Pearson's correlation coefficient.

\section{Results}

\section{Baseline characteristics of lung cancer patients and control subjects}

A detailed description of subjects concerning age, histologic types of lung cancer, clinical stages of disease, level of education, and smoking status is presented in Table 1. The majority of LW and LM (88.6\% and 89.6\%, respectively) suffered from non-small-cell lung cancer (NSCLC). Subjects from LG were diagnosed with different clinical stages of disease - more than half at stages I and IV. The CW subjects were significantly better educated than those from LW; however, no significant differences in self-reported educational level were observed between LM and CM. Both study groups were differentiated by smoking status. A significantly higher percentage of LG regardless of sex were former or current smokers in comparison with CG.

\section{Dietary intakes, glycemic index and glycemic load of diets}

The energy content, carbohydrates, dietary fiber intake, and the GI and GL of diets are presented in Table 2. The energy provided from diets, the total and available carbohydrates, and the ratio of available to total carbohydrates were higher in LW and LM when compared to CW and CM, respectively. The intake of dietary fiber in LM was significantly higher than in CM, but after recalculating per $1,000 \mathrm{kcal}$, the intake of dietary fiber was significantly

Table 1. Baseline characteristics of sex-related groups of lung cancer and control subjects

\begin{tabular}{|c|c|c|c|c|c|c|c|c|}
\hline Variable & $\mathrm{n}$ & LW & $\mathrm{n}$ & $\mathrm{CW}$ & $\mathrm{n}$ & LM & $\mathrm{n}$ & $\mathrm{CM}$ \\
\hline $\begin{array}{l}\text { Age (median (min-max)) } \\
\text { [years] }\end{array}$ & 82 & $66(41-82)^{\mathrm{a}}$ & 78 & $56(24-77)^{\mathrm{a}}$ & 98 & $64(38-82)^{a}$ & 93 & $59(23-98)^{a}$ \\
\hline $\begin{array}{l}\text { Type of cancer (NSCLC/ } \\
\text { SCLS) [\%] }\end{array}$ & 44 & $88.6 / 11.4$ & 78 & $\mathrm{n} / \mathrm{a}$ & 58 & $89.6 / 10.4$ & 93 & $\mathrm{n} / \mathrm{a}$ \\
\hline $\begin{array}{l}\text { Clinical stage of disease } \\
(\mathrm{I} / \mathrm{I} / \mathrm{I} \mid \mathrm{la} / \mathrm{IIb} / \mathrm{IV})[\%]\end{array}$ & 38 & $52.6 / 18.4 / 7.9 / 5.3 / 15.8$ & 78 & $\mathrm{n} / \mathrm{a}$ & 51 & $31.4 / 13.6 / 11.8 / 11.8 / 31.4$ & 93 & $\mathrm{n} / \mathrm{a}$ \\
\hline $\begin{array}{l}\text { Educational level } \\
\text { (primary/secondary/ } \\
\text { vocational/university) [\%] }\end{array}$ & 80 & $13.8 / 45.0 / 22.5 / 18.8^{b}$ & 77 & $3.9 / 48.0 / 10.4 / 37.7^{b}$ & 96 & $18.8 / 29.2 / 38.5 / 13.5$ & 91 & $12.1 / 35.2 / 30.8 / 21.9$ \\
\hline $\begin{array}{l}\text { Smoking status (former } \\
\text { smoker/current smoker/ } \\
\text { never-smoker) [\%] }\end{array}$ & 58 & $65.5 / 20.7 / 13.8^{b}$ & 78 & 23.1/17.9/59. $0^{b}$ & 75 & $78.7 / 16 / 5.3^{b}$ & 91 & $29.7 / 29.7 / 40.6^{b}$ \\
\hline
\end{tabular}

LW - lung cancer women; CW - control women; LM - lung cancer men; CM - control men; ${ }^{\text {a }}$ - statistically significant differences demonstrated by Student's t-test or Mann-Whitney U test between sex-related groups of lung cancer and control subjects; $\mathrm{p}<0.05$; $b$ - statistically significant differences demonstrated by the $x^{2}$ test between sex-related groups of lung cancer and control subjects, $p<0.05$ (observed significant differences between compared groups are in bold); NSCLC - non-small-cell lung cancer; SCLC - small-cell lung cancer; n/a - not applicable. 
Table 2. Energy, carbohydrate, dietary fiber intake and dietary Gl and GL in the diets of sex-related groups of lung cancer and control subjects: median (min-max)

\begin{tabular}{|c|c|c|c|c|c|c|c|c|}
\hline Variable & $\mathrm{n}$ & LW & $\mathrm{n}$ & $C W$ & $\mathrm{n}$ & LM & $\mathrm{n}$ & $\mathrm{CM}$ \\
\hline Energy content $[\mathrm{kcal} / \mathrm{d}]$ & 82 & $\begin{array}{c}2019.3 \\
(1160.1-3196.5)\end{array}$ & 78 & $\begin{array}{c}1840.6 \\
(1023.4-3018.9)\end{array}$ & 98 & $\begin{array}{c}2763.7 \\
(1558.1-3978.4)\end{array}$ & 93 & $\begin{array}{c}2149.6 \\
(1077.0-3995.4)\end{array}$ \\
\hline $\begin{array}{l}\text { Total carbohydrate content } \\
{[\mathrm{g} / \mathrm{d}]}\end{array}$ & 82 & $\begin{array}{c}283.4 \\
(155.4-477.8)\end{array}$ & 78 & $\begin{array}{c}260.7 \\
(122.1-431.4)\end{array}$ & 98 & $\begin{array}{c}361.7 \\
(187.8-561.8)\end{array}$ & 93 & $\begin{array}{c}283.7 \\
(148.3-598.2)\end{array}$ \\
\hline $\begin{array}{l}\text { Total carbohydrate content } \\
{[\mathrm{g} / 1,000 \mathrm{kcal}]}\end{array}$ & 82 & $\begin{array}{c}141.2 \\
(99.8-183.2)\end{array}$ & 78 & $\begin{array}{c}140.9 \\
(94.2-183.5)\end{array}$ & 98 & $\begin{array}{c}128.5 \\
(91.6-165.4)\end{array}$ & 93 & $\begin{array}{c}129.4 \\
(90.6-166.6)\end{array}$ \\
\hline $\begin{array}{l}\text { Available carbohydrate } \\
\text { content }[\mathrm{g} / \mathrm{d}]\end{array}$ & 82 & $\begin{array}{c}263.2 \\
(139.9-446.1)\end{array}$ & 78 & $\begin{array}{c}234.7 \\
(111.8-389.2)\end{array}$ & 98 & $\begin{array}{c}332.6 \\
(165.9-534.4)\end{array}$ & 93 & $\begin{array}{c}255.6 \\
(125.4-554.0)\end{array}$ \\
\hline $\begin{array}{l}\text { Available carbohydrate } \\
\text { content }[\mathrm{g} / 1,000 \mathrm{kcal}]\end{array}$ & 82 & $\begin{array}{c}129.2 \\
(89.9-167.9)\end{array}$ & 78 & $\begin{array}{c}128.4 \\
(84.9-166.6)\end{array}$ & 98 & $\begin{array}{c}118.1 \\
(82.2-153.7)\end{array}$ & 93 & $\begin{array}{c}119.3 \\
(84.8-155.0)\end{array}$ \\
\hline $\begin{array}{l}\text { Ratio of available and total } \\
\text { carbohydrates [\%] }\end{array}$ & 82 & $\begin{array}{c}92.2 \\
(86.1-96.4)\end{array}$ & 78 & $\begin{array}{c}91.1 \\
(84.6-95.0)\end{array}$ & 98 & $\begin{array}{c}92.5 \\
(87.7-95.1)\end{array}$ & 93 & $\begin{array}{c}91.5 \\
(84.5-96.1)\end{array}$ \\
\hline Dietary fiber content [g/d] & 82 & $\begin{array}{c}21.6 \\
(13.1-50.6)\end{array}$ & 78 & $\begin{array}{c}22.7 \\
(8.7-45.6)\end{array}$ & 98 & $\begin{array}{c}27.6 \\
(12.7-46.9)\end{array}$ & 93 & $\begin{array}{c}23.5 \\
(8.2-54.3)\end{array}$ \\
\hline $\begin{array}{l}\text { Dietary fiber content } \\
{[\mathrm{g} / 1,000 \mathrm{kcal}]}\end{array}$ & 82 & $\begin{array}{c}11.1 \\
(4.7-19.9)\end{array}$ & 78 & $\begin{array}{c}12.4 \\
(6.3-21.6)\end{array}$ & 98 & $\begin{array}{c}9.6 \\
(6.6-15.9)\end{array}$ & 93 & $\begin{array}{c}10.9 \\
(5.0-22.2)\end{array}$ \\
\hline $\mathrm{Gl}[\%]$ & 82 & $\begin{array}{c}52.3 \\
(45.5-60.5)\end{array}$ & 78 & $\begin{array}{c}50.6 \\
(33.0-67.9)\end{array}$ & 98 & $\begin{array}{c}53.6 \\
(44.1-61.4)\end{array}$ & 93 & $\begin{array}{c}54.5 \\
(34.6-69.2)\end{array}$ \\
\hline $\mathrm{GL}[\mathrm{g} / \mathrm{d}]$ & 82 & $\begin{array}{c}152.5 \\
(72.6-256.9)\end{array}$ & 78 & $\begin{array}{c}132 \\
(59.2-233.2)\end{array}$ & 98 & $\begin{array}{c}198.6 \\
(92.3-320.9)\end{array}$ & 93 & $\begin{array}{c}155.4 \\
(51.3-320.3)\end{array}$ \\
\hline $\mathrm{GL} / 1,000 \mathrm{kcal}$ & 82 & $\begin{array}{c}74.4 \\
(51.5-102.1)\end{array}$ & 78 & $\begin{array}{c}69.1 \\
(44.3-93.9)\end{array}$ & 98 & $\begin{array}{c}68.4 \\
(45.04-87.70)\end{array}$ & 93 & $\begin{array}{c}73.2 \\
(47.6-106.8)\end{array}$ \\
\hline
\end{tabular}

Differences were assessed using the Mann-Whitney $U$ test or Student's t-test between sex-related groups of lung cancer and control subjects; $\mathrm{p}<0.05$ (significant differences between compared groups are in bold); LM - lung cancer men; CM - control men; LW - lung cancer women; CW - control women; Gl-glycemic index; GL - glycemic load.

lower in LW and LM than in CW and CM. Interestingly, although the GI of diets was significantly higher in LW than in $\mathrm{CW}$, the opposite relationship was observed between LM and CM. Additionally, we found significantly higher GL in the lung cancer women and men when compared to the GL of diets in the control women and men, respectively; however, we did not further observe this difference when recalculating the GL per 1,000 kcal.

\section{Nutritional status}

Data concerning nutritional status was assessed based on anthropometric parameters and are presented in Table 3. The nutritional status of the lung cancer patients was worse than that of the controls, as demonstrated mainly by the significantly lower weight, HC, CC, and MAC in LM compared to CM, and the significantly higher WHR and lower CC in LW in comparison with CW.

\section{Biochemical measurements regarding antioxidant/oxidant status and circulating glucose}

The results concerning biochemical measurements of antioxidant/oxidant status and circulating glucose are presented in Table 4 . The analysis revealed significant differences in the antioxidant/oxidant status between the lung cancer patients and the control subjects, demonstrated by the significantly lower antioxidant capacity (TAS) and the higher oxidative stress (OSI) in LW and LM compared to $\mathrm{CW}$ and $\mathrm{CM}$, respectively, and the significantly higher oxidative status (TOS), only in the men. However, no differences in MDA level were observed between lung cancer and control subjects. The LW and LM groups had significantly higher levels of circulating GLC as well as INS, which in turn led to significantly higher values of HOMAIR compared to CW and CM.

\section{Correlations between variables related to antioxidant/oxidant status and glucose, anthropometric parameters, nutrient intake, and GI and GL values in the lung cancer and control groups}

Correlation analysis revealed various significant relationships between antioxidant/oxidant status and the parameters related to glucose, anthropometric parameters and nutrient intake in sex-differentiated groups of lung cancer and control subjects (Table 5). In LW, we found significant positive correlations between TAS and WC, HC, weight and BMI. Additionally in LW, we observed a significant negative correlation between OSI and energy content and available and total carbohydrate content, as well as a positive correlation between OSI and GLC. Moreover, TAS in CW had a positive association with CC, WC and 
Table 3. Anthropometric parameters of sex-related groups of lung cancer patients and control subjects: median (min-max)

\begin{tabular}{|c|c|c|c|c|c|c|c|c|}
\hline Variable & $\mathrm{n}$ & LW & $\mathrm{n}$ & $C W$ & $\mathrm{~N}$ & LM & $\mathrm{n}$ & $\mathrm{CM}$ \\
\hline Weight [kg] & 82 & $\begin{array}{c}65 \\
(40-106)\end{array}$ & 78 & $\begin{array}{c}69 \\
(46-98)\end{array}$ & 97 & $\begin{array}{c}75 \\
(47-146)\end{array}$ & 82 & $\begin{array}{c}81 \\
(52-118)\end{array}$ \\
\hline $\mathrm{BMI}\left[\mathrm{kg} / \mathrm{m}^{2}\right]$ & 82 & $\begin{array}{c}26.2 \\
(16.8-44.1)\end{array}$ & 78 & $\begin{array}{c}25.9 \\
(16.8-37.1)\end{array}$ & 97 & $\begin{array}{c}25.6 \\
(17.9-51.7)\end{array}$ & 82 & $\begin{array}{c}26.3 \\
(18.4-38.7)\end{array}$ \\
\hline FFMI $\left[\mathrm{kg} / \mathrm{m}^{2}\right]$ & 53 & $\begin{array}{c}17.7 \\
(14.1-22.8)\end{array}$ & 46 & $\begin{array}{c}17.4 \\
(14.3-25.5)\end{array}$ & 72 & $\begin{array}{c}19.4 \\
(13.2-30.0)\end{array}$ & 55 & $\begin{array}{c}19.7 \\
(15.2-24.6)\end{array}$ \\
\hline BFP [\%] & 53 & $\begin{array}{c}33.8 \\
(11.8-50.0)\end{array}$ & 46 & $\begin{array}{c}36.5 \\
(19.7-47.7)\end{array}$ & 72 & $\begin{array}{c}24.5 \\
(6.7-44.0)\end{array}$ & 55 & $\begin{array}{c}26.1 \\
(6.2-37.7)\end{array}$ \\
\hline$W C[\mathrm{~cm}]$ & 56 & $\begin{array}{c}94 \\
(62-128)\end{array}$ & 67 & $\begin{array}{c}86 \\
(63-119)\end{array}$ & 73 & $\begin{array}{c}94.5 \\
(74-141)\end{array}$ & 73 & $\begin{array}{c}99 \\
(74-120)\end{array}$ \\
\hline $\mathrm{HC}[\mathrm{cm}]$ & 56 & $\begin{array}{c}103 \\
(65-141)\end{array}$ & 67 & $\begin{array}{c}103 \\
(80-120)\end{array}$ & 73 & $\begin{array}{c}98 \\
(81-137)\end{array}$ & 72 & $\begin{array}{c}102 \\
(63-115)\end{array}$ \\
\hline WHR & 56 & $\begin{array}{c}0.899 \\
(0.688-1.292)\end{array}$ & 67 & $\begin{array}{c}0.832 \\
(0.692-1.188)\end{array}$ & 73 & $\begin{array}{c}0.967 \\
(0.822-1.138)\end{array}$ & 72 & $\begin{array}{c}0.971 \\
(0.768-1.202)\end{array}$ \\
\hline$C C[\mathrm{~cm}]$ & 33 & $\begin{array}{c}34.0 \\
(27.2-42.3)\end{array}$ & 30 & $\begin{array}{c}37.8 \\
(32.5-42.3)\end{array}$ & 35 & $\begin{array}{c}34.3 \\
(28.5-41.0)\end{array}$ & 42 & $\begin{array}{c}36.0 \\
(29.0-46.0)\end{array}$ \\
\hline $\mathrm{MAC}[\mathrm{cm}]$ & 48 & $\begin{array}{c}29.0 \\
(20.8-36.0)\end{array}$ & 40 & $\begin{array}{c}30.0 \\
(24.7-37.0)\end{array}$ & 68 & $\begin{array}{c}28.1 \\
(23.3-39.1)\end{array}$ & 53 & $\begin{array}{c}30.0 \\
(22.0-37.0)\end{array}$ \\
\hline
\end{tabular}

Differences were assessed using the Mann-Whitney $U$ test or Student's t-test between sex-related groups of lung cancer patients and control subjects; $p<0.05$ (observed significant differences between compared groups are in bold); LW - lung cancer women; CW - control women; LM - lung cancer men; CM - control men; BMI - body mass index; FFMI - fat-free mass index; BFP - body fat percentage; WC - waist circumference; HC - hip circumference; WHR - waist-to-hip ratio; CC - calf circumference; MAC - mid-arm circumference.

Table 4. Serum levels of parameters of redox status as well as glucose, insulin and HOMA-IR values in sex-related groups of lung cancer and control subjects: median (min-max)

\begin{tabular}{|c|c|c|c|c|c|c|c|c|}
\hline Variable & $\mathrm{n}$ & LW & $\mathrm{n}$ & $C W$ & $n$ & LM & $\mathrm{n}$ & $\mathrm{CM}$ \\
\hline TAS [mmol Trolox equiv./L] & 71 & $\begin{array}{c}1.51 \\
(0.96-2.34)\end{array}$ & 77 & $\begin{array}{c}1.64 \\
(1.25-2.14)\end{array}$ & 81 & $\begin{array}{c}1.62 \\
(1.17-2.55)\end{array}$ & 42 & $\begin{array}{c}1.85 \\
(1.42-2.10)\end{array}$ \\
\hline TOS $\left[\mu \mathrm{mol} \mathrm{H}_{2} \mathrm{O}_{2}\right.$ equiv./L] & 69 & $\begin{array}{c}3.32 \\
(0.27-74.79)\end{array}$ & 73 & $\begin{array}{c}2.50 \\
(0.10-48.63)\end{array}$ & 73 & $\begin{array}{c}5.22 \\
(0.39-52.13)\end{array}$ & 42 & $\begin{array}{c}3.14 \\
(0.51-74.79)\end{array}$ \\
\hline OSI [arbitrary unit] & 62 & $\begin{array}{c}2.093 \\
(0.151-52.301)\end{array}$ & 73 & $\begin{array}{c}1.402 \\
(0.055-32.691)\end{array}$ & 69 & $\begin{array}{c}2.712 \\
(0.000-37.773)\end{array}$ & 42 & $\begin{array}{c}1.774 \\
(0.345-51.938)\end{array}$ \\
\hline MDA $[\mu \mathrm{mol} / \mathrm{L}]$ & 74 & $\begin{array}{c}1.715 \\
(0.310-4.480)\end{array}$ & 76 & $\begin{array}{c}1.553 \\
(0.000-15.625)\end{array}$ & 82 & $\begin{array}{c}1.804 \\
(0.559-7.728)\end{array}$ & 42 & $\begin{array}{c}1.882 \\
(0.000-6.574)\end{array}$ \\
\hline Glucose [mg/dL] & 71 & $\begin{array}{c}107.1 \\
(33.8-296.0)\end{array}$ & 77 & $\begin{array}{c}86.5 \\
(68.2-231.6)\end{array}$ & 78 & $\begin{array}{c}97.8 \\
(57.0-286.0)\end{array}$ & 42 & $\begin{array}{c}87.0 \\
(69.6-296.0)\end{array}$ \\
\hline Insulin $[\mu \mathrm{U} / \mathrm{mL}]$ & 38 & $\begin{array}{c}16.6 \\
(3.9-112.7)\end{array}$ & 41 & $\begin{array}{c}10.6 \\
(3.8-25.0)\end{array}$ & 57 & $\begin{array}{c}18.6 \\
(3.1-132.0)\end{array}$ & 33 & $\begin{array}{c}10.2 \\
(5.4-62.5)\end{array}$ \\
\hline HOMA-IR [arbitrary unit] & 38 & $\begin{array}{c}5.12 \\
(0.75-68.29)\end{array}$ & 41 & $\begin{array}{c}2.23 \\
(0.86-5.74)\end{array}$ & 57 & $\begin{array}{c}5.10 \\
(0.49-81.58)\end{array}$ & 33 & $\begin{array}{c}2.08 \\
(1.19-45.71)\end{array}$ \\
\hline
\end{tabular}

Differences between groups were assessed using the Mann-Whitney $U$ test or Student's t- test between lung cancer and control groups (significant differences between compared groups are in bold); $\mathrm{p}<0.05$; LW - lung cancer women; CW - control women; LM - lung cancer men; CM - control men; TAS - total antioxidant status; TOS - total oxidant status; OSI - oxidative stress index; MDA - malondialdehyde; HOMA-IR - homeostasis model assessment for insulin resistance.

weight, but a negative one with dietary fiber and total carbohydrate content. In CW, TOS and OSI had negative correlations with weight and BMI and positive ones with INS. In LM, we only found a positive correlation between TOS and GI. In CM, we observed a significant negative correlation between TAS and GLC as well as HOMA-IR. On the other hand, TOS and OSI correlated positively with GLC, INS and HOMA-IR in this subgroup. For the first time, out of all the subgroups, we found a positive correlation between MDA and BMI as well as weight in CM.

\section{Discussion}

It has been confirmed that antioxidant/oxidant status changes in lung cancer, as well as in many other site-specific cancers, and a depletion of antioxidant capacity has been observed along with tumor progression. ${ }^{27}$ Despite this, the mechanisms of redox disturbance in lung cancer patients are still not entirely clear. Cigarette smoking and lung inflammation, as well as systemic inflammation, are recognized as major causes of depletion of antioxidant 
Table 5. Significant correlations between variables related to concentrations of glucose, anthropometric parameters, nutrient intake, Gl, GL, and parameters related to antioxidant/oxidant status in sex-related groups of lung cancer and control subjects

\begin{tabular}{|c|c|c|c|}
\hline Correlation & $\mathrm{N}$ & $\mathrm{R}$ & $\mathrm{p}$-value \\
\hline \multicolumn{4}{|l|}{ LW } \\
\hline TAS vs WC & 48 & 0.2997 & 0.039 \\
\hline TAS vs HC & 48 & 0.3164 & 0.028 \\
\hline TAS vs weight & 71 & 0.3317 & 0.005 \\
\hline TAS vs BMI & 71 & 0.2374 & 0.046 \\
\hline OSI vs energy content & 62 & -0.2669 & 0.036 \\
\hline OSI vs available carbohydrate content & 62 & -0.2763 & 0.030 \\
\hline OSI vs total carbohydrate content & 62 & -0.2737 & 0.031 \\
\hline OSI vs glucose & 57 & 0.3126 & 0.018 \\
\hline \multicolumn{4}{|l|}{$C W$} \\
\hline TAS vs CC & 30 & 0.3622 & 0.049 \\
\hline TAS vs WC & 66 & 0.2553 & 0.039 \\
\hline TAS vs weight & 77 & 0.2322 & 0.042 \\
\hline TAS vs dietary fiber & 77 & -0.3032 & 0.007 \\
\hline TAS vs total carbohydrate content & 77 & -0.2328 & 0.042 \\
\hline TOS vs weight & 73 & -0.2732 & 0.019 \\
\hline TOS vs BMI & 73 & -0.2672 & 0.022 \\
\hline TOS vs insulin & 39 & 0.3326 & 0.039 \\
\hline OSI vs weight & 73 & -0.2924 & 0.012 \\
\hline OSI vs BMI & 73 & -0.2802 & 0.016 \\
\hline OSI vs insulin & 39 & 0.3384 & 0.035 \\
\hline \multicolumn{4}{|l|}{ LM } \\
\hline TOS vs Gl & 73 & 0.2460 & 0.036 \\
\hline \multicolumn{4}{|l|}{$C M$} \\
\hline TAS vs glucose & 42 & -0.3341 & 0.031 \\
\hline TAS vs HOMA-IR & 33 & -0.3445 & 0.050 \\
\hline TOS vs glucose & 42 & 0.8204 & $<0.001$ \\
\hline TOS vs insulin & 33 & 0.8287 & $<0.001$ \\
\hline TOS vs HOMA-IR & 33 & 0.9237 & $<0.001$ \\
\hline OSI vs glucose & 42 & 0.8563 & $<0.001$ \\
\hline OSI vs insulin & 33 & 0.8417 & $<0.001$ \\
\hline OSI vs HOMA-IR & 33 & 0.9527 & $<0.001$ \\
\hline MDA vs weight & 42 & 0.3146 & 0.042 \\
\hline MDA vs BMI & 42 & 0.5102 & 0.001 \\
\hline
\end{tabular}

LW - lung cancer women; CW - control women; LM - lung cancer men; CM - control men; TAS - total antioxidant status; WC - waist circumference, $\mathrm{HC}$ - hip circumference; BMI - body mass index; OSI - oxidative stress index; TOS - total oxidant status; CC - calf circumference; GI - glycemic index; MDA - malondialdehyde; HOMA-IR - homeostasis model assessment for insulin resistance.

pools. ${ }^{28}$ However, other factors may at least partially contribute to this imbalance. Although the link between the GI and GL of diets and oxidative stress is known in the general population, ${ }^{29}$ no data concerning this correlation in cancer patients, including lung cancer ones, has been described. The purpose of this study was therefore to assess the relationship between GI, GL and nutritional status and antioxidant/oxidant status in lung cancer patients.

In this study, we demonstrated elevated systemic oxidative stress and depletion of antioxidant capacity in lung cancer patients when compared to control subjects, which suggests that changes in whole body redox status are at least partially associated with lung cancerogenesis. The disruption of antioxidant/oxidant status in lung tissue has been considered one of the key factors of lung cancerogenesis at the molecular level. ${ }^{30}$ However, extensive studies into the detailed mechanisms of systemic alterations in the antioxidant/oxidant status of lung cancer patients have not been conducted. Expanding our knowledge in this area could bring new perspectives into lung cancer pathophysiology. Disruptions in metabolism during cancerogenesis are well-known and are often observed in lung cancer patients, leading to, i.e., malnutrition and altered glucose utilization. ${ }^{31,32}$ Elevated circulating glucose (and in consequence, elevated insulin levels) result in a high prevalence of insulin resistance among lung cancer patients. Insulin resistance was proven to be an additional risk factor for lung cancer in 1 study, ${ }^{28}$ though the mechanisms concerning the role of insulin resistance in lung cancerogenesis were not studied in that work. ${ }^{33}$ In our study, alterations in glucose metabolism were also observed, expressed as higher glucose and insulin concentrations and HOMA-IR levels, in the lung cancer patients than in the control subjects. Evidence presented by Ceriello ${ }^{34}$ shows that persistent elevated blood glucose is highly toxic. It induces insulin resistance and impairs insulin secretion by pancreatic $\beta$-cells. ${ }^{34}$ During chronic hyperglycemia and in the early phase of hyperinsulinemia, free radicals are formed disproportionately and/or impaired antioxidant defenses are observed. ${ }^{29,35}$ In addition to metabolic alterations occurring during cancerogenesis, such as a less efficient Cori cycle, hyperglycemia may also result from an imbalanced diet rich in available carbohydrates and with a high GI and/or GL. ${ }^{36}$ It would be interesting to see whether dietary intakes with a proven impact on glucose homeostasis are different between the lung cancer and general populations, as this could be an additional factor contributing to glucose alterations. In this study we found that lung cancer patients consumed significantly higher total as well as available carbohydrate content and demonstrated a higher ratio of available to total carbohydrates, while dietary fiber content expressed in $\mathrm{g} / 1,000 \mathrm{kcal}$ of food intake was significantly lower in the lung cancer patients than in the control group. These results suggest that the lung cancer patients' diets were worse than the control subjects' in terms of the quality and quantity of carbohydrates. This resulted in the observed higher GI and GL of the diets of lung cancer patients compared to the control subjects. Melkonian et al. also observed a higher GI of diets and lower dietary fiber intakes by lung cancer patients than control subjects, though there were no differences in the GL of diets or total carbohydrate content. ${ }^{37}$ 
Moreover, the abovementioned authors found an important association between GI (not GL of diets) and lung cancer risk in the studied group of non-Hispanic whites. Also, a link between high GI or GL and an increased risk of prevalence was observed in other site-specific cancers. ${ }^{38}$ On the other hand, a study conducted by $\mathrm{Hu}$ et al. found no significant associations between the GI of diets and the risk of lung cancer ${ }^{39}$; therefore, more studies concerning these relationships should be carried out.

Although some studies have been designed to ascertain the impact of GI and/or the GL of diets on the risk of different site-specific cancers, ${ }^{37,39,40}$ associations between GI or GL and antioxidant/oxidant status have not been assessed, either in lung cancer patients or in other cancerrelated populations. The most frequently described mechanism of cancerogenesis related to a high GI and/or GL of diets is based on the direct mitogenic effect exerted by a high level of insulin and on the indirect effect: by affecting insulin-like growth factors (IGF) and binding proteins (IGFBPs) and by increasing the bioactivity of IGF-I. Circulating insulin as well as IGF-1 may inhibit apoptosis and therefore lead to the immortality of cancer cells. ${ }^{39}$ Despite the undeniable role of insulin, IGF and IGFBPs in lung cancerogenesis, an altered antioxidant/oxidant status related to a high GI and/or high GL also seems to be important in lung cancer management, also due to the fact that a large cohort study on a healthy population did not find any association between hs-CRP (an indicator of systemic inflammation) and GI or GL, which showed that another mechanism (other than a pro-inflammatory one) may be linked with metabolic alterations and a high GI or GL of diets. ${ }^{41}$ Therefore, finding potential relationships between them in a population with lung cancer may provide additional data on the pathogenesis of this disease.

In this study, we found a significant positive association between GI and TOS, but only in men with lung cancer; however, in women with lung cancer, circulating glucose positively correlated with the index of oxidative stress. These results indicate that a high GI and/or GL may influence the redox balance by intensifying oxidative stress, in addition to other, non-dietary factors, e.g., cancer development and metabolic disturbances. Interestingly, in the control subjects, we observed more relationships between the parameters of antioxidant/oxidant status and biochemical parameters related to circulating glucose. Among the control men, glucose concentration positively correlated with TOS and OSI, which consequently resulted in positive relationships between the parameters of oxidant status and insulin level and HOMA-IR. Moreover, in the control women, these relationships were weaker and observed only with insulin levels, which suggests that the observed dependencies may be strongly related to gender.

High-GI foods are characterized by fast-release carbohydrates and the results of a sharp increase in blood glucose level, including a greater insulin demand. ${ }^{15}$ Acute increases in blood glucose concentration may promote the production of free radicals by non-enzymatic glycation and by an imbalance in the ratio of NADH to NAD ${ }^{+}$ induced by glucose in the cells. ${ }^{14}$ This is the mechanism most commonly mentioned to account for the relationship between high dietary GI and increased oxidative stress. ${ }^{42}$ $\mathrm{Hu}$ et al. ${ }^{14}$ examined the associations of GI and GL with the plasma oxidative stress markers, MDA and isoprostane (IsoPS) concentration. They found that a low GI, not a lowcarbohydrate diet, appears to be beneficial in reducing oxidative stress. In our study of lung cancer patients, we also observed a significant correlation between the parameters of oxidative stress and GI, but not with GL.

In the crossover clinical study by Botero et al., a 10-day low-GI dietary intervention was compared with a high-GI diet in overweight or obese patients. ${ }^{43}$ The results showed significantly higher plasma total antioxidant activity under fasting conditions and during the postprandial period on the $7^{\text {th }}$ day, but no differences were observed in cardiovascular disease risk biomarkers, such as insulin sensitivity, acute insulin response, total cholesterol, HDL, triglycerides, etc. ${ }^{43}$ This study suggests that the parameters of one's antioxidant/oxidant balance are primarily affected by the GI of one's diet, before any other biochemical variables, and may therefore provide a quick answer as to the impact of GI on systemic homeostasis. Moreover, the meta-analysis of the long-term effects of low GI and GL performed by Schwingshackl and Hoffmann showed decreases in C-reactive proteins and fasting insulin concentrations, as well as fat-free mass in obesity subjects, while no changes were observed in the levels of lipid profile biomarkers. ${ }^{44}$ In the study by Pittas et al., a beneficial effect on serum CRP concentration was also observed. ${ }^{45}$ In our study as in the studies presented above, parameters of circulating glucose significantly correlated with oxidant status; moreover, in the control subjects these correlations were stronger than in the lung cancer patients, probably due to the additional effects of cancerogenesis and cancer-related malnutrition on redox balance among the lung cancer patients. However, we did not find any correlations between fat-free mass index and the parameters of redox status, regardless of the group.

In this study, we observed that the nutritional status of lung cancer patients, mainly women, was associated with total antioxidant capacity rather than with parameters related to oxidative stress: TOS and OSI. This suggests that a reduction in antioxidant capacity may be associated with cancer-related malnutrition. Interestingly, in the control subjects, we found that nutritional status was linked with parameters of antioxidant status and oxidative stress, and that TAS positively correlated with calf circumference, waist circumference and weight; however, more statistically significant relationships were observed between parameters related to body mass and oxidative stress. Based on the observed correlations, we concluded that in healthy people, a high body mass may intensify oxidative stress, while in a population with cancer-related 
metabolic alterations of nutritional status, mainly related to muscles, these alterations may be additional factors which influence antioxidant capacity. Indeed, several studies have confirmed at the tissue and molecular level that cancer-related cachexia may negatively affect redox balance. ${ }^{46,47}$ Marin-Corral et al. found that malnutrition related to cancer disrupted antioxidant/oxidant status in the muscles and hearts of rats, increasing oxidative modifications of key proteins involved in muscle structure and function. ${ }^{46}$ In a study performed on men with severe chronic obstructive pulmonary disease (COPD) and lung cancer, Puig-Vilanova et al. observed that cachectic patients had significantly higher levels of muscle protein oxidation and ubiquitination, and that redox-sensitive signaling pathways like nuclear factor kappa B (NF-kB) and Forkhead box $\mathrm{O}$ (FoxO) were activated. ${ }^{47}$ Moreover, structural and functional protein levels were lower in the muscles of malnourished patients, regardless of the disease, while levels of autophagy markers were increased only in the muscles of COPD patients and not in healthy subjects. In this study, however, we did not observe any differences in FFMI, an independent parameter of muscle status, between the lung cancer and control groups, nor was any correlation of parameters related to antioxidant/ oxidant status with FFMI or BFP found. On the other hand, in control subjects we observed that MDA, a parameter of lipid oxidation, positively correlated with weight as well as BMI. A high body mass is closely related to an altered redox balance. Mechanisms involved in obesity-related disruption in antioxidant status and an increase in ROS resulted in systemic oxidative stress concerning hyperleptinemia, hyperglycemia and hyperlipidemia and an increase of pro-inflammatory cytokine levels, as well as endothelial dysfunction. ${ }^{48}$ It is interesting whether sex determines the observed differences in these relationships, since in women, regardless of the occurrence of cancer, parameters of nutritional status were related to a redox state, while in men it was mainly the parameters related to glucose that were linked with parameters of oxidative stress. This could, at least partially, result from differences in the activity of sex hormones. In a study by Barp et al. performed on female and male rats, it was demonstrated that estrogen may have an antioxidant role, while testosterone does not..$^{49}$ Moreover, in men (mainly in the control subjects) we observed a higher waist circumference than in women, which could also strengthen correlations with parameters of oxidative stress. ${ }^{50}$

\section{Conclusions}

The results presented in this study show that in lung cancer patients, parameters of oxidative stress are related to GI and alterations in glucose concentration, but not to nutritional status, while total antioxidant status is associated more with nutritional status, but not with parameters related to glucose concentration or GI and GL of diets. The observed relationships are strongly determined by sex. Further investigations performed on a larger cohort are required to better clarify the observed relationships and to explain the potential mechanisms involved.

\section{References}

1. Torre LA, Bray F, Siegel RL, Ferlay J, Lortet-Tieulent J, Jemal A. Global cancer statistics, 2012. CA Cancer J Clin. 2015;65(2):87-108. doi:10. 3322/caac. 21262

2. Wojciechowska U, Didkowska J. Zachorowania i zgony na nowotwory złośliwe w Polsce. Krajowy Rejestr Nowotworów, Centrum Onkologii - Instytut im. Marii Skłodowskiej-Curie. http://onkologia.org. pl/raporty/. Accessed June 23, 2018.

3. Wang A, Kubo J, Luo J, et al. Active and passive smoking in relation to lung cancer incidence in the Women's Health Initiative Observational Study prospective cohort. Ann Oncol. 2015;26(1):221-230. doi:10.1093/annonc/mdu470

4. Filaire E, Dupuis C, Galvaing G, et al. Lung cancer: What are the links with oxidative stress, physical activity and nutrition. Lung Cancer. 2013;82(3):383-389. doi:10.1016/J.LUNGCAN.2013.09.009

5. Wang Y, Li F, Wang Z, Qiu T, Shen Y, Wang M. Fruit and vegetable consumption and risk of lung cancer: A dose-response meta-analysis of prospective cohort studies. Lung Cancer. 2015;88(2):124-130.

6. Misthos P, Katsaragakis S, Milingos N, et al. Postresectional pulmonary oxidative stress in lung cancer patients: The role of one-lung ventilation. Eur J Cardiothorac Surg. 2005;27(3):379-383. doi:10.1016/j. ejcts.2004.12.023

7. Rahman I, Biswas SK, Kode A. Oxidant and antioxidant balance in the airways and airway diseases. Eur J Pharmacol. 2006;533(1-3):222-239. doi:10.1016/J.EJPHAR.2005.12.087

8. Gharibvand L, Shavlik D, Ghamsary M, et al. The association between ambient fine particulate air pollution and lung cancer incidence: Results from the AHSMOG-2 study. Environ Health Perspect. 2017; 125(3):378-384. doi:10.1289/EHP124

9. Saha SK, Lee S Bin, Won J, et al. Correlation between oxidative stress, nutrition, and cancer initiation. Int J Mol Sci. 2017;18(7):1544. doi:10. 3390/ijms18071544

10. Khare M, Mohanty C, Das BK, Jyoti A, Mukhopadhyay B, Mishra SP. Free radicals and antioxidant status in protein energy malnutrition. Int J Pediatr. 2014;2014:1-6. doi:10.1155/2014/254396

11. Mantovani G, Madeddu C, Macciò A. Cachexia and oxidative stress in cancer: An innovative therapeutic management. Curr Pharm Des. 2012;18(31):4813-4818. doi:10.2174/138161212803216889

12. Russo GL, Tedesco I, Spagnuolo C, Russo M. Antioxidant polyphenols in cancer treatment: Friend, foe or foil? Semin Cancer Biol. 2017;46:1-13. doi:10.1016/j.semcancer.2017.05.005

13. Pitsavos C, Panagiotakos DB, Tzima N, Chrysohoou C, Economou M. Adherence to the Mediterranean diet is associated with total antioxidant capacity in healthy adults: The ATTICA study. Am J Clin Nutr. 2005;82(3):694-699.

14. Hu Y, Block G, Norkus EP, Morrow JD, Dietrich M, Hudes M. Relations of glycemic index and glycemic load with plasma oxidative stress markers. Am J Clin Nutr. 2006;84(1):70-77. doi:10.1093/ajcn/84.1.70

15. Dudziak K, Regulska-llow B. The importance of glycemic load of the diet in the development of cancer. Postepy Hig Med Dosw (Online). 2013;67:449-462. doi:10.5604/17322693.1050032

16. Erel O. A new automated colorimetric method for measuring total oxidant status. Clin Biochem. 2005;38(12):1103-1111. doi:10.1016/j.clinbiochem.2005.08.008

17. Aycicek A, Erel O, Kocyigit A. Decreased total antioxidant capacity and increased oxidative stress in passive smoker infants and their mothers. Pediatr Int. 2005;47(6):635-639.

18. Jacobo-Cejudo MG, Valdés-Ramos R, Guadarrama-López AL, PardoMorales RV, Martínez-Carrillo BE, Harbige LS. Effect of n-3 polyunsaturated fatty acid supplementation on metabolic and inflammatory biomarkers in type 2 diabetes mellitus patients. Nutrients. 2017;9(6):573.

19. Schutz Y, Kyle UUG, Pichard C. Fat-free mass index and fat mass index percentiles in Caucasians aged 18-98 y. Int J Obes Relat Metab Disord. 2002;26(7):953-960. 
20. Schröder H, Covas MI, Marrugat J, et al. Use of a three-day estimated food record, a 72-hour recall and a food-frequency questionnaire for dietary assessment in a Mediterranean Spanish population. Clin Nutr. 2001;20(5):429-437.

21. Szponar L, Rychlik E, Wolnicka K; Instytut Żywności i Żywienia im. Aleksandra Szczygła. Album fotografii produktów i potraw. Warszawa, Poland: Instytut Żywności i Żywienia; 2008.

22. Kunachowicz H. Przygoda B. Nadolna I. Iwanow K. Tabele składu i wartości odżywczejżywności. Warszawa, Poland: Wydawnictwo Lekarskie PZWL; 2017.

23. Louie JCY, Flood V, Turner N, Everingham C, Gwynn J. Methodology for adding glycemic index values to 24-hour recalls. Nutrition. 2011; 27(1):59-64. doi:10.1016/j.nut.2009.12.006

24. Atkinson FS, Foster-Powell K, Brand-Miller JC. International Tables of Glycemic Index and Glycemic Load Values: 2008. Diabetes Care. 2008;31(12):2281-2283.

25. The University of Sydney. Glycemic Index Research Service 2007. www.glycemicindex.com. Accessed on April 20, 2018.

26. National Cancer Institute. Diet History Questionnaire Database File 2006.http://riskfactor.cancer.gov/DHQ/database/dhq1_032806.csv

27. Zabłocka-Słowińska K, Porębska I, Gołecki M, et al. Total antioxidant status in lung cancer is associated with levels of endogenous antioxidants and disease stage rather than lifestyle factors: Preliminary study. Contemp Oncol (Pozn). 2016;20(4):302-307. doi:10.5114/wo. 2016.61850

28. Rahman I, MacNee W. Role of oxidants/antioxidants in smokinginduced lung diseases. Free Radic BiolMed. 1996;21(5):669-681. doi:10. 1016/0891-5849(96)00155-4

29. Marfella R, Quagliaro L, Nappo F, Ceriello A, Giugliano D. Acute hyperglycemia induces an oxidative stress. JClin Invest. 2001;108(4):635-636. doi:10.1172/JCI0113727A

30. Azad N, Rojanasakul Y, Vallyathan V. Inflammation and lung cancer: Roles of reactive oxygen/nitrogen species. J Toxicol Environ Heal B Crit Rev. 2008;11(1):1-15. doi:10.1080/10937400701436460

31. Arends J, Baracos V, Bertz H, et al. ESPEN expert group recommendations for action against cancer-related malnutrition. Clin Nutr. 2017; 36(5):1187-1196. doi:10.1016/j.clnu.2017.06.017

32. Heber D, Chlebowski RT, Ishibashi DE, Patients C, Herrold JN, Block JB. Abnormalities in glucose and protein metabolism in noncachectic lung cancer patients. Cancer Res. 1982;42(11):4815-4819.

33. Petridou ET, Sergentanis TN, Antonopoulos CN, et al. Insulin resistance: An independent risk factor for lung cancer? Metabolism. 2011; 60(8):1100-1106. doi:10.1016/j.metabol.2010.12.002

34. Ceriello A. Postprandial hyperglycemia and diabetes complications: Is it time to treat? Diabetes. 2005;54(1):1-7. doi:10.2337/DIABETES. 54.1.1

35. Rajendran $\mathrm{P}$, Nandakumar $\mathrm{N}$, Rengarajan $\mathrm{T}$, et al. Antioxidants and human diseases. Clin Chim Acta. 2014;436(7):332-347. doi:10.1016/j. cca.2014.06.004

36. Klement RJ, Kämmerer U. Is there a role for carbohydrate restriction in the treatment and prevention of cancer? Nutr Metab. 2011;8(1):75. doi:10.1186/1743-7075-8-75
37. Melkonian SC, Daniel CR, Ye Y, Pierzynski JA, Roth JA, Wu X. Glycemic index, glycemic load, and lung cancer risk in non-Hispanic whites. Cancer Epidemiol Biomarkers Prev. 2016;25(3):532-539. doi:10.1158/ 1055-9965.EPI-15-0765

38. Romieu I, Ferrari P, Rinaldi S, et al. Dietary glycemic index and glycemic load and breast cancer risk in the European Prospective Investigation into Cancer and Nutrition (EPIC). Am J Clin Nutr. 2012;96(2): 345-355.

39. Hu J, La Vecchia C, Augustin LS, et al; Canadian Cancer Registries Epidemiology Research Group. Glycemic index, glycemic load and cancer risk. Ann Oncol. 2013;24:245-251. doi:10.1093/annonc/mds235

40. Turati F, Galeone C, Gandini S, et al. High glycemic index and glycemic load are associated with moderately increased cancer risk. Mol Nutr Food Res. 2015;59(7):1384-1394. doi:10.1002/mnfr.201400594

41. Griffith JA, Ma Y, Chasan-Taber L, et al. Association between dietary glycemic index, glycemic load, and high-sensitivity C-reactive protein. Nutrition. 2008;24(5):401-406.

42. Augustin LSA, Kendall CWC, Jenkins DJA, et al. Glycemic index, glycemic load and glycemic response: An International Scientific Consensus Summit from the International Carbohydrate Quality Consortium (ICQC). Nutr Metab Cardiovasc Dis. 2015;25(9):795-815. doi:10.1016/j. numecd.2015.05.005

43. Botero D, Ebbeling CB, Blumberg JB, et al. Acute effects of dietary glycemic index on antioxidant capacity in a nutrient-controlled feeding study. Obesity (Silver Spring). 2009;17(9):1664-1670. doi:10.1038/ oby. 2009.203

44. Schwingshackl L, Hoffmann G. Long-term effects of low glycemic index/load vs. high glycemic index/load diets on parameters of obesity and obesity-associated risks: A systematic review and meta-analysis. Nutr Metab Cardiovasc Dis. 2013;23(8):699-706. doi:10.1016/j. numecd.2013.04.008

45. Pittas AG, Roberts SB, Das SK, et al. The effects of the dietary glycemic load on type 2 diabetes risk factors during weight loss. Obesity (Silver Spring). 2006;14(12):2200-2209.

46. Marin-Corral J, Fontes CC, Pascual-Guardia S, et al. Redox balance and carbonylated proteins in limb and heart muscles of cachectic rats. Antioxid Redox Signal. 2010;12(3):365-380. doi:10.1089/ars.2009.2818

47. Puig-Vilanova E, Rodriguez DA, Lloreta J, et al. Oxidative stress, redox signaling pathways, and autophagy in cachectic muscles of male patients with advanced COPD and lung cancer. Free Radic Biol Med. 2015;79:91-108. doi:10.1016/j.freeradbiomed.2014.11.006

48. Savini I, Catani MV, Evangelista D, Gasperi V, Avigliano L. Obesityassociated oxidative stress: Strategies finalized to improve redox state. Int JMol Sci. 2013;14(5):10497-10538. doi:10.3390/ijms140510497

49. Barp J, Araújo ASDR, Fernandes TRG, et al. Myocardial antioxidant and oxidative stress changes due to sex hormones. Braz J Med Biol Res. 2002;35(9):1075-1081.

50. Furukawa S, Fujita T, Shimabukuro M, et al. Increased oxidative stress in obesity and its impact on metabolic syndrome. J Clin Invest. 2017; 114(12):1752-1761. 